\section{Septic Oligoarthritis Caused by Klebsiella pneumoniae and Acinetobacter baumannii}

\section{To the Editor:}

Septic arthritis is an uncommon and potentially fatal emergency associated with significant mortality and morbidity rates, with an incidence in the general population reported to be 2 to 5 per $100,000^{1}$. Bacteria may spread directly from adjacent osteomyelitis or from a local soft-tissue infection, diagnostic or therapeutic procedure, or penetrating trauma ${ }^{1}$. Usually, this condition is caused by $S$. aureus, which accounts for two-thirds of the cases, whereas septic arthritis caused by Klebsiella pneumoniae or Acinetobacter baumannii are rare conditions seldom reported $2,3,4,5$. We describe a case of an adult male with oligoarthritis septic arthritis due to extended-spectrum beta-lactamase $K$. pneumoniae and imipenem-resistent A. baumannii after arthroscopic surgery of the knee. To our knowledge, this is the first report of a patient with septic oligoarthritis simultaneously coinfected by the pathogens $K$. pneumoniae and A. baumannii.

A 52-year-old man underwent arthroscopic surgery of the right knee because of a meniscal lesion. After 5 months, he developed signs of oligoarthritis in both elbows and on the operated knee. Examination showed all 3 articulations were swollen and hot, with signs of articular effusion, periarticular pain, and partial limitation of movement. Blood count and biochemical markers did not show any relevant characteristics. Erythrocyte sedimentation rate and C-reactive protein levels were elevated ( $95 \mathrm{~mm} / \mathrm{h}$ and $236 \mathrm{mg} / \mathrm{dl}$, respectively), and remained high throughout the next 7 months. He underwent open surgery of both elbows and arthrocentesis of the right knee to collect material for culture and analysis of the synovial fluid. He then progressed to a septic state and to acute respiratory failure and received broad-spectrum antibiotics, initially oxacillin and meropenem, with the purpose of covering both gram-positive and -negative germs. The bacterial culture of the synovial fluids and Kirby-Bauer antibiotic testing revealed extended-spectrum beta-lactamase $K$. pneumoniae in both elbows and imipenem-resistent $A$. baumannii in the right knee. All the hemocultures were negative. He received a combination of vancomycin and polymyxin B. In consequence of his general condition he was sent to the intensive care unit, where he remained for 45 days. After discharge, he maintained functional capacity of the joints, although he could not fully extend both elbow joints. He did not develop any other complications such as osteomyelitis or pyomyositis.

This case is unusual for several reasons. First, nongonococcal bacterial arthritis usually affects only 1 joint, most commonly the knee, while polyarticular involvement occurs in only $10 \%$ to $15 \%$ of cases, usually in patients with rheumatoid arthritis, systemic connective tissue disorder, or overwhelming sepsis ${ }^{6,7,8,9}$. Second, most cases are caused by $S$. aureus, whereas only $15 \%$ of cases are caused by gram-negative bacteria, which are most commonly seen in immunocompromised and elderly patients ${ }^{2,4,10}$. Third, although $K$. pneumoniae is a common cause of gram-negative bloodstream infection, septic arthritis caused by this pathogen is a rare condition in adult patients. Even though the mortality rate from septic arthritis caused by K. pneumoniae is relatively low, around $7.1 \%$, early recognition and treatment of the infection is important to reduce complications such as joint destruction ${ }^{3,4}$. Finally, septic arthritis caused by A. baumannii is hardly ever reported; however, the incidence of nosocomial infections has been increasing, consequently, infections caused by $A$. baumannii must be treated immediately to prevent nosocomial cross-infection and bacterial spread ${ }^{11}$. It is a challenging task to treat infections caused by antibiotic-resistant bacteria, and such infections are likely to cause multiple organ failure and death ${ }^{11}$.

MAURICIO F.S. MARCHI, Medical Student; RAFAEL S. GOMES, MD, MSc, Fundação Universidade Regional de Blumenau, Department of Medicine, Antônio da Veiga, N. 140, Health Sciences Department, J-105 Blumenau, Santa Catarina 89012-900, Brazil. Address correspondence to Dr. Gomes; E-mail: gomesmed2002@ibest.com.br

\section{REFERENCES}

1. Kherani RB, Shojania K. Septic arthritis in patients with pre-existing inflammatory arthritis. CMAJ 2007;176:1605-8.

2. Mathews CJ, Weston VC, Jones A, Field M, Coakley G. Bacterial septic arthritis in adults. Lancet 2010;375:846-55.

3. Kohler JE, Hutchens MP, Sadow PM, Modi BP, Tavakkolizadeh A, Gates JD. Klebsiella pneumoniae necrotizing fasciitis and septic arthritis: An appearance in the Western hemisphere. Surg Infect 2007;8:227-32.

4. Schelenz S, Bramham K, Goldsmith D. Septic arthritis due to extended spectrum beta lactamase producing Klebsiella pneumoniae. Joint Bone Spine 2007;74:275-8.

5. Markusse HM, Timmerman RJ. Infectious arthritis caused by Klebsiella. A report of two cases. Clin Rheumatol 1989;8:517-21.

6. Nade S. Septic arthritis. Best Pract Res Clin Rheumatol 2003; 17:183-200.

7. Dubost JJ, Soubrier M, Sauvezie B. Pyogenic arthritis in adults. Joint Bone Spine 2000;67:11-21.

8. Carpenter CR, Schuur JD, Everett WW, Pines JM. Evidence-based diagnostics: adult septic arthritis. Acad Emerg Med 2011;18:781-96

9. Goldenberg DL. Septic arthritis. Lancet 1998;351:197-202.

10. García-Arias M, Balsa A, Mola EM. Septic arthritis. Best Pract Res Clin Rheumatol 2011;25:407-21.

11. Duan X, Yang L, Xia P. Septic arthritis of the knee caused by antibiotic-resistant Acinetobacter baumannii in a gout patient: A rare case report. Arch Orthop Trauma Surg 2010;130:381-4.

J Rheumatol 2013;40:7; doi:10.3899/jrheum.130117 